\title{
The Tourism Concept of Emergency Shelter: Strategies for Community Resilience in The Coastal Area of South Lampung
}

\author{
D Hardilla $^{1}$ K H Basuki ${ }^{1}$ F Rusmiati ${ }^{1}$ C Persada $^{1 *}$
}

\author{
${ }^{1}$ Department of Architecture, University of Lampung, Bandar Lampung, Indonesia \\ *Corresponding author. Email: citra.persada@eng.unila.ac.id
}

\begin{abstract}
Facing vulnerability of disaster in the coastal area, a disaster risk reduction planning is evolved in Kalianda as the capital of South Lampung regency. These district areas close to Mount Anak Krakatoa which one of the most active volcano in Indonesia and caused the underwater landslide then turn generated a tsunami. One of the disaster risk reduction strategies is build an emergency shelter for evacuate residents and improve disaster preparedness infrastructure. Actually, the effectiveness of emergency shelter was used during disaster and after that it might never be used by residents. There was an opportunity to develop tourism concept and strategies for improving the effectiveness of emergency shelter. This paper aims to provide a new perspective and strategies for the effectiveness of emergency shelter as the community-based tourism planning. This paper begins with reviews practical case studies of communitybased tourism in vulnerable areas and concludes the elements for community-based tourism strategies. The analysis shows that four key elements of the community-based tourism strategies: 1) sustainable infrastructure, 2) human attitudes toward disaster, 3) local community empowerment and 4) collaborative governance. Emergency shelter as sustainability infrastructure will become a tourism business incubator, which should provide diverse benefits of social, and economy development strategies. Residents can highlight the neighbourhood's history and the perseverance of human spirit in the disaster's aftermath. Besides as a new livelihood for residents, the community-based tourism revenue can support the operational cost of emergency shelter and another disaster risk reduction programs.
\end{abstract}

Keywords: Shelter, Resilience, Tourism, Community, Anak Krakatoa

\section{INTRODUCTION}

Indonesia has a high potential for seismic earthquakes. This is due to Indonesia's geographical location at the intersection of the Eurasian, IndoAustralian, and Philippine Sea tectonic plates. This is associated with the fast motion of plates at the Sumatera seductions zone accommodating $49 \mathrm{~mm} /$ year of oblique convergence. Lateral displacement causes large damaging earthquakes (e.g. Mw 7.6 in 1943) and Tsunami. The epicentre has tied to the seduction plate with the position following the seduction zone, which then caused a Tsunami in Indonesia [13][1]. Probabilistic hazard analysis shows high vulnerability across Sumatera and low to moderate hazard across the Malaysia Peninsula, including Lampung [2].

Bandar Lampung, which is the western part of Lampung Province, located near the Sunda Strait seduction zone, has active movement and high seismic levels. Based on the results of BPPT research, Bandar Lampung known as the third zone (Zone III) of five (5) tsunami vulnerability zones in the Sunda Strait region. Tsunami in this region caused by the topographical condition of the south coast of Bandar Lampung, which is a tsunami-prone bay, potentially earthquakes, floods and environmental damage [3]. Tsunami will also increase by dense settlements along the coast, and the eruption of Mount Krakatoa in the waters of the Sunda Strait.

Eruption of Mount Krakatoa part of Sumatera Island is an outstanding example of high vulnerability across Sumatera conditions. Mount Krakatoa was erupted with high banging force, heard all the way to Burma and Australia, in the afternoon, August 26, 1883. The mountain exploded and released large volcanic material, resulting in crater wounds, and sank Mount Krakatoa. In 
addition, the eruption of this mountain also boils the seawater, creating tsunami waves as high as more than 10 meters, destroying Banten and Anyer on the island of Java, as well as Lampung on the island of Sumatra. This condition indirectly concerns the entire population in all three regions. Tsunami waves also spread throughout the Indian Ocean and France. Other materials, such as the volcanic ash eruption of Mount Krakatoa surround the Earth's atmosphere, creating spectacular sunsets for two years around the world [4].

Mount Krakatoa is still active today, where the ventilation of this mountain creates a small island in the middle of the caldera. The small island flourished during a major eruption in 1883, known as Mount Anak Krakatoa, meaning children of Krakatoa. On 22 December 2018 a Tsunami was generated from the area of Mount Anak Krakatoa, with waves propagating in all directions inside the Sunda Strait, the sea portion between the Java and Sumatera islands. The Tsunami caused fatalities and extensive damage along the coastal areas of Sunda Strait. As of 24 December morning, there were at least 281 deaths, mostly in Pandeglang (Banten Province, Java), 57 people missing, 1016 injured, more than 700 structures damaged and 350 boats damaged [5]. Past and future strategic for disaster risk reduction of Mount Anak Krakatoa is shown in Figure 1.

\section{3}

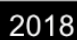

2025

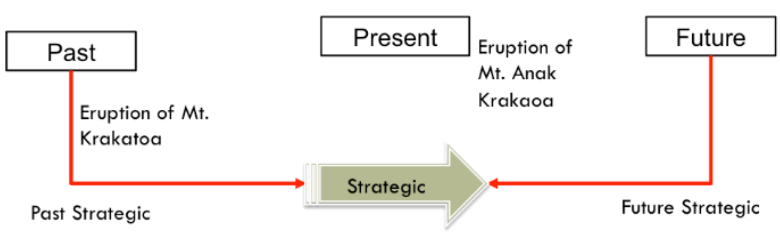

Figure 1 Past and Future Strategic for Disaster Risk Reduction of Mount Anak Krakatoa in The Coastal Area of South Lampung

In this perspective, one of the disaster risk reduction strategies is build an emergency shelter for evacuate residents and improve disaster preparedness infrastructure. Actually, the effectiveness of emergency shelter was used during disaster and after that residents might never use it. There was an opportunity to develop tourism concept and strategies for improving the effectiveness of emergency shelter. Emergency shelter as sustainability infrastructure will become a tourism business incubator, which should provide diverse benefits of social, and economy development strategies. Residents can highlight the neighbourhood's history and the perseverance of human spirit in the disaster's aftermath. Besides as a new livelihood for residents, the community-based tourism revenue can support the operational cost of emergency shelter and another disaster risk reduction programs.
The motivation of research on the concept of tourism in disaster emergency shelters through coastal community resilience strategies, it is necessary to first understand the vulnerability zone itself. Stakeholders consisting of policy makers, public institutions, communities, and the private sector have an important responsibility in building emergency shelter centers for the community, so that the community can save themselves and have disaster preparedness. The stage of making the concept of shelters and tourism facilities can provide services to people who survived the disaster. Tourism is vulnerable sector that has been experiencing major crises from disaster. Disaster emergency shelters using the tourism concept approach can provide guidance and guidance related to building desian, so that building construction policies can improve the socio-ecological aspects of the environment. In addition, this concept is also used to respond, as well as adapt earthquakes and tsunamis throughout the coastal areas of South Lampung [3][4]. Tourism concept of emergency shelter is considered as a large and unique collection of industry sectors with special need in disaster planning and recovery. Tourism is especially vulnerable to disaster and, being fragmented, often its response is difficult to initiate and coordinate. So, to imagine tourism concept of emergency shelter and community resilience's strategies, we need analyses community capacity of all the strengths and resources that exist within a community, society or organization in coastal area of South Sumatera.

\section{METHODS}

The research is intending to provide a new perspective and strategies for the effectiveness of emergency shelter as the community-based tourism planning. This paper begins with reviews a practical case study of community-based tourism in vulnerable areas and concludes the elements for community-based tourism strategies. The analysis shows that four key elements of the community-based tourism strategies: 1) sustainable infrastructure, 2) human attitudes toward disaster, 3) local community empowerment and 4) collaborative governance. This paper describes the organizational framework between local governance, the private sectors and community to build community-based tourism affairs. We conclude that it can spread disaster preparedness education, supporting socio-economy of community resilience and become a practical framework of community resilience strategies.

\section{RESULT AND DISCUSSION}

\subsection{Strategies for Community's Resilience}

Communities are create from various ages, circles, social strata, cultures, where each individual has the same challenges and opportunities in the face of disaster hazards. Resilience as part of urban planning strategies 
and strengthening communities in adapting from global, climate, social, cultural, natural disasters, industry, and economic shocks. This concept of resilience provides signs in the sea, sky and wildlife to predict hazards and provide guidance for local communities. This concept will be collaborated with local knowledge gained through disaster management experience, disaster frequency, intensity, so as to predict possible hazard behavior and formulate its handling strategy.

In fact, resilience is the ability of a person or group of people to prepare, adapt according to change, survive and recover quickly from the impact of change. A focus on resilience means putting greater emphasis on what communities can do for themselves and how to strengthen their capacities, rather than concentrating on their vulnerability to disaster or environmental shocks and stresses, or their needs in an emergency.

Resilience creates the ability to withstand and recover from attacks, accidents, disasters, threats or events that occur spontaneously over a short period [6]. People need to have resilience to disasters, both at the environmental and national level, through a system that is structured and in accordance with their needs [7][8]. The implementation process of this resilience concept starts from the identification and mapping of hazards based on the frequency and extent of damage produced, so as to formulate a holistic governance plan in dealing with social problems, infrastructure improvements due to disasters, and the ability to finance the recovery process due to disasters. Community support could help to smooth the development suggested that resident's.

\subsection{Tourism Concept of Emergency Shelter as Sustainable Infrastructure}

Post-disaster development is an important topic that has been studied by various scholars in different aspects. Many previous studies focused on the recovery policies and approaches [9][10][11][12], planning of reconstruction [11][13][14], management of infrastructure reconstruction [15][11], and community resilience [16][11][19] in natural hazard prone country such as Japan. However, these studies never dealing with tourism concept for emergency shelter design.

The implementation of tourism concept can be successful to construct disaster shelters, if it obtains support from local communities, during the disaster reconstruction process. The concept is considered part of a labor-intensive industry that has high job opportunities without investment [18][19][20]. In addition, the application of Tourism concept can also change the perspective of the community in using imported goods, so as to indirectly increase the promotion of local products [13][15]. People who has suffering from economic stagnation can make tourists and migrants as their investors in the future [21][18]. Thus, the concept of tourism in the post-disaster period became one of the tools in realizing the resilience of the community, through the creation of the basic characters of tourism.

Disaster management through tourism concept can be interpreted as a form of knowledge for tourists to study the situation of disaster areas, so that they can adapt and participate in supporting the regional economy by spending money in the local market. Although this concept has an advantage for the local community, but this concept also gets criticism and rejection, because it is considered to display the experience of tragedy from the local community, thus providing a different perspective, where disasters can open the disgrace of the system of social, ecological and cultural structures of local communities [18][22]. Disaster Management that uses the concept of pariwisara can change the view of the community towards the region, where the disaster area can become a tourist attraction.

In this study, disaster tourism will perform as concept for emergency shelter where is a part of 4-stage disaster circumstance.

Temporary shelters are the first stage in determining the reconstruction of disaster impacts. At this stage, survivors are removed from disaster-affected shelters to temporary shelters. This stage becomes the determining stage of survival of the survivors, where we must be able to meet all their needs. These needs are not merely material aids such as facilities, food, and fabrics. But also sanitation, privacy, recreation and others are required. The construction of disaster emergency shelters is the second stage in the implementation of resilience strategies in the post-disaster period. While the final stage of the implementation is the pre-disaster period through the prevention process [23]. Figure 2 shows the distaster tourism concept of Mount Anak Krakatoa which supports various function of activities, i.e.: shelter, education, economy, early warning system, torism, and social community.

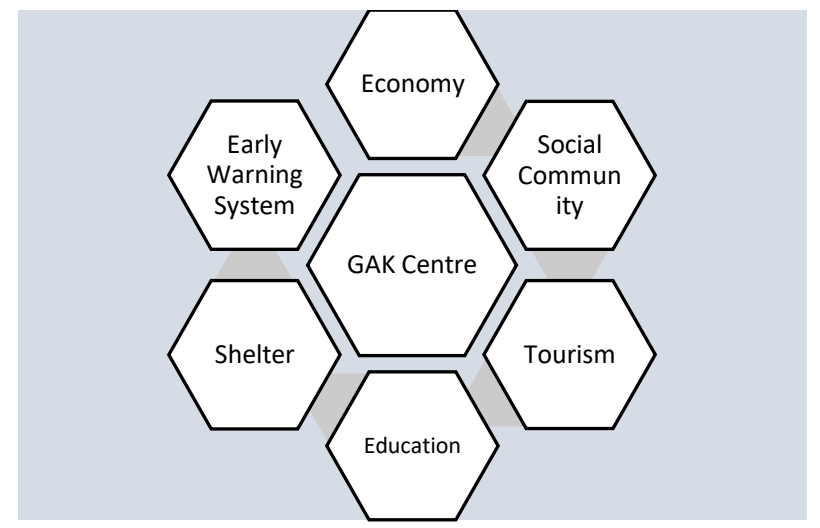

Figure 2 Goal of Disaster Tourism Concept of Mount Anak Krakatoa

Based on this stage, we aim design-planning solutions for emergency management situations where design is 
innovative, inclusive, sustainable, save, have community, design concepts in coastal area of South Lampung is affordable and interactive learning. Emergency shelter shown on Figure 3

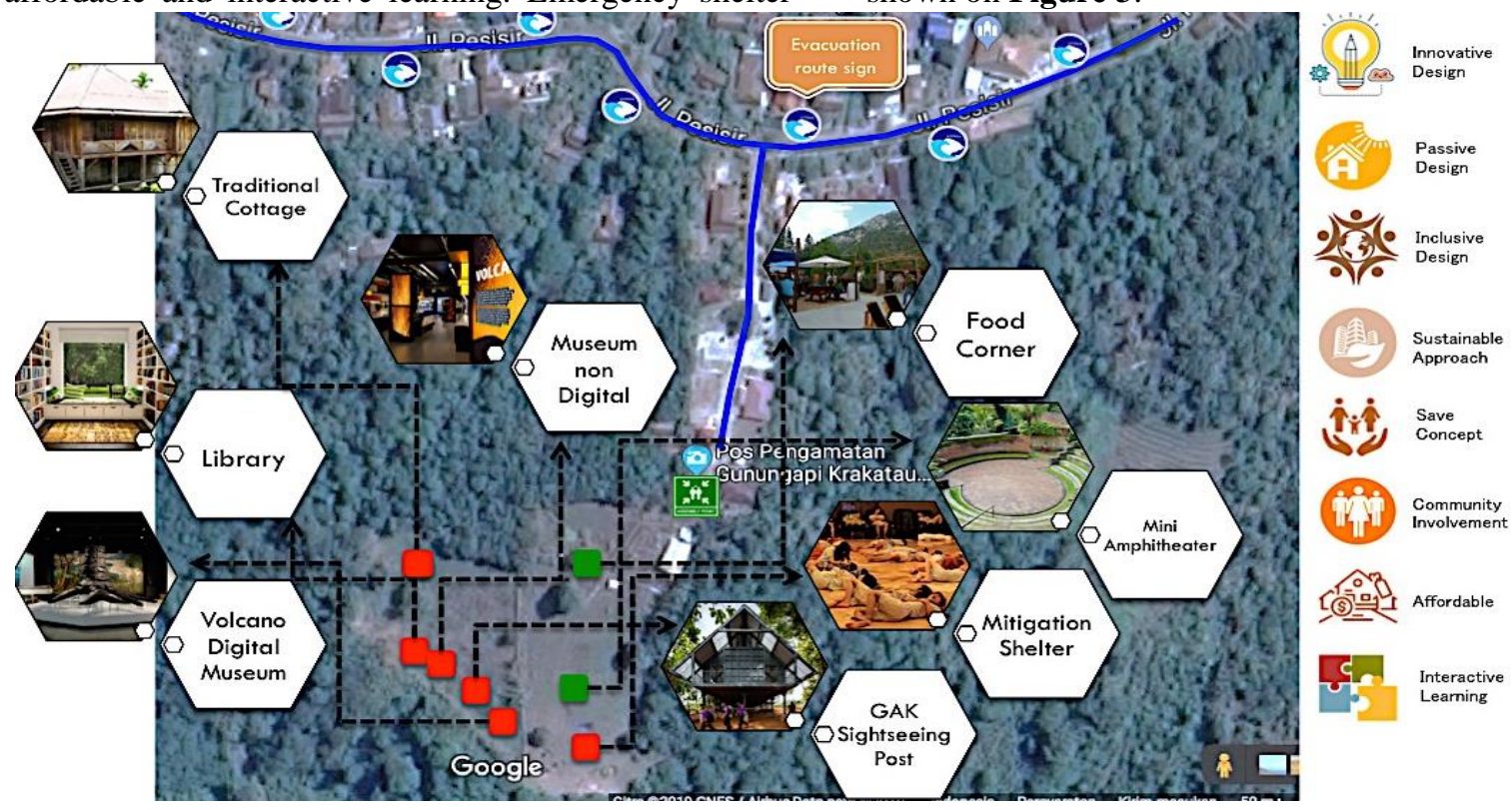

Figure 1 Emergency Shelter Design Concepts in the Coastal Area of South Lampung

In addition, the emergency shelter was also design to be able to accommodate the needs for 7 days after the disaster by providing an integrated system of food, medicine, clothing, clean water and energy systems that were connect through the control room. On the recovery stage, this building can function as tourism facilities such as digital museums, libraries and cottages that have traditional Lampung architecture.
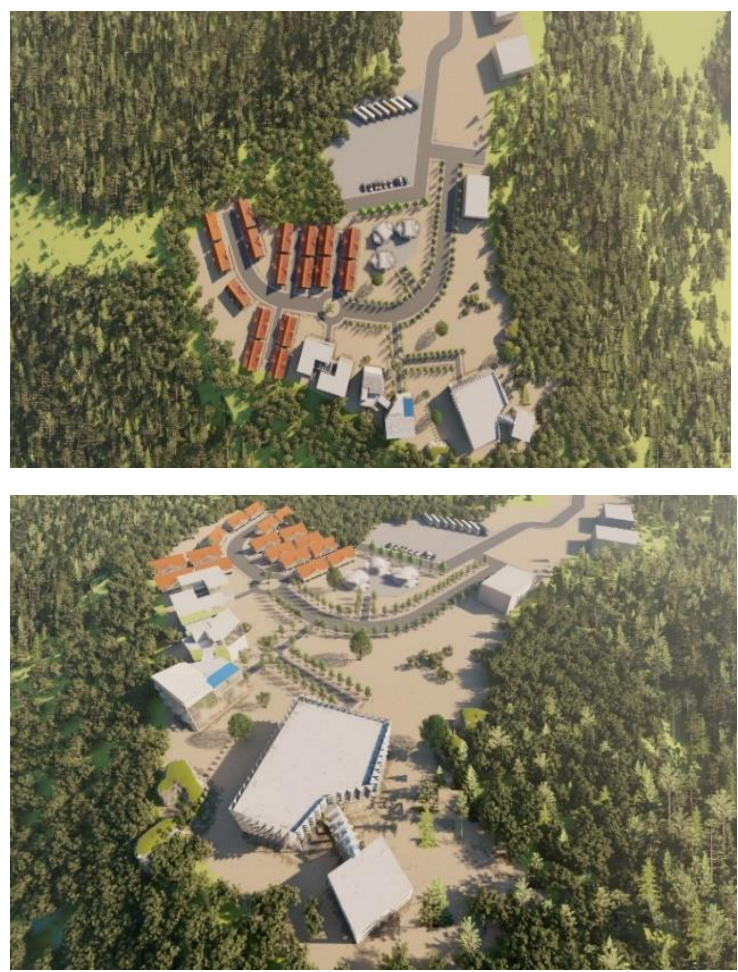

Figure 4 Design of Emergency Shelter in The Coastal Area of South Lampung.

\section{CONCLUSION}

Based on the results of the analysis, it can concluded that the concept of tourism in emergency shelters is a potential strategy, which can create community resilience in coastal areas of South Lampung. It is observe that the basis of tourism concept and the main goals of emergency shelter are both in the same direction. Social, history, economic, mitigation, and environmental have concern that are the pillars of emergency shelter as sustainability that can at the same time be easily understood in the buildings which are designed and built by locals in the coastal area of South Lampung. The purpose of this study was to offer design-planning solutions for emergency management situations. According to analysis, designplanning solution will cover economy resilience, cyber resilience, building resilience, social community resilience, technology resilience, energy development and resilience. The study present is design to be able to provide benefit for both of past and future development.

\section{ACKNOWLEDGMENTS}

We would like to thank (Ikatan Alumni) IA-ITB Lampung and citizens of South Lampung Regency, especially citizen at near Mount Anak Krakatoa and the coastal area for providing us data and information. This research was perform under the supervision of Architecture Department, Lampung University.

\section{REFERENCES}

[1] M. Diawati, Y. Sanada, Investigation and Analysis of Buildings Damage during the September 2007 
Sumatera, Indonesia Earthquakes, Journal of Asian Architecture and Building Engineering, vol.7 no.2., 2008.

[2] P. Gruber, U. Herbig, Research of Environmental Adaptation of Traditional Building Constructions and Techniques in Nias in CIPA 2005 XX International Symposium, 26 September - 01 October, 2005, Torino, Italy.

[3] Alhamidi, V.H. Pakpahan, J. E. S. Simanjuntak, Analysis of tsunami disaster resilience in Bandar Lampung Bay Coastal Zone in The 4th PlanoCosmo International Conference, 2018, IOP Publishing. IOP Conf. Series: Earth and Environmental Science 158 (2018) 012037.

[4] T. Giachetti, K.Kelfoun, R. Paris, Tsunami Hazard related to flank collapsed of Anak Krakatoa Vulcano, Sunda Strait, Indonesia, 2012.

[5] A.S. Marguerite, Indonesia to investigate origins of 'silent' Sunda Strait tsunami after volcano collapse, 2018. The Jakarta Post. https://www.thejakartapost.com/news/2018/12/25/ indonesia-to-investigate-origins-of-silent-sundastrait-tsunami-after-volcano-collapse.html.

[6] J. Twigg, Characteristics of a disaster-resilient community: a guidance note (version 2), Researchgate, 2009. https://www.researchgate.net/publication/3056155 $\underline{92}$

[7] Y. Morakabati,, S. J. Page, and J. Fletcher, Emergency Management and Tourism Stakeholder Responses to Crises: A Global Survey. Journal of Travel Research, 2017, Vol. 56(3) 299-316.

[8] The Joint Committee of Indonesia and Japan on Disaster Reduction, Building Resilience of Indonesia and Its Communities to Disaster for the Next Generation, 2006.

[9] D. Abramson, Y. Qi, Urban-rural integration in the earthquake zone: Sichuan's post-disaster reconstruction and the expansion of the Chengdu metropole. Pac. Aff., 2011, 84, 495-523. [CrossRef].

[10] S. Henly-Shepard, C. Anderson, K. Burnett, L.J. Cox, J.N. Kittinger, M.A. Ka'aumoana, Quantifying household social resilience: A placebased approach in a rapidly transforming community. Nat. Hazards, 2015, 75, 343-363. [CrossRef].

[11] S. Liu, T.O. Lewis, Cheung, Y.L. Alex, and F. Wei., Livelihood Benefits from Post-Earthquake Nature-
Based Tourism Development: A Survey of Local Residents in Rural China. MDPI. Sustainable, 2018.

[12] Y. Shao, J. $\mathrm{Xu}$, Regulating post-disaster reconstruction planning in china: Towards a resilience-based approach? Asian Geogr. 2017, 34, 71-89. [CrossRef]

[13] K.D. Regmi, The political economy of 2015 Nepal earthquake: Some critical reflections. Asian Geogr., 2016, 33, pp77-96. [CrossRef]

[14] Z. Yang, Z. Chun, D. William, O. Robert, Planning and recovery following the great 1976 Tangshan earthquake. J. Plan. Hist., 2015, 14, pp 224-243.

[15] E. Hayat, D. Amaratunga, The role of local government in post-disaster road reconstruction: Assessment of factors affecting local government road maintenance capacity. In Disaster Risk Reduction in Indonesia: Progress, Challenges, and Issues; Djalante, R., Garschagen, M., Thomalla, F., Shaw, R., Eds.; Springer International Publishing: Cham, Switzerland, 2017; pp. 255-279.

[16] H.J. Boon, Disaster resilience in a flood-impacted rural Australian town. Nat. Hazards, 2014, 71, 683701. [CrossRef]

[17] C.-H. Tsai, T.-C. Wu, G. Wall, S.-C. Linliu, Perceptions of tourism impacts and community resilience to natural disasters. Tour. Geogr.,2016, 18, pp 152-173. [CrossRef]

[18] N. Nagai,. Disaster Tourism The Role of Tourism in Post-Disaster Period of Great East Japan Earthquake. Institute National Study. The Hague, The Netherlands, 2012.

[19] H. Sano, Shinsai to Kanko (Earthquake Disaster and Tourism - Strength and Weakness of Tourism in Disaster Reconstruction), Koryu Bunka (Cul- tural Exchange) (12), 2011.

[20] N. Yamada, Fukko no Jiku Ni Resilience (Resilience can be an Essence of the Reconstruction)' The Yomiuri Shimbun, 05.15, 2012. p. 28.

[21] R. Govers, From Place Marketing to Place Branding and Back. Place Branding and Public Diplomacy, 2011, 7(4) p.227.

[22] A. Oliver-Smith, Anthropological Research on Hazards and Disasters', Annual Review of Anthropology, 1996, 25(1) pp.303-328.

[23] H. Ghimire, Disaster Management and Post-quake Impact on Tourism in Nepal. Journal of Tourism and Hospitality (vol.7). Article in Geological Society London Special Publications, January 2012, DOI: 10.1144/SP361.7. 